\title{
Influence of age factor in the treatment of Ilizarov orthopedic diseases and injuries of the limbs.
}

\section{Schurov VA*}

Department of Medical Sciences, Ilizarov Research Center for Rehabilitating Traumatology and Orthopedics, Kurgan, Russia

\begin{abstract}
Background: The review of the author's own research, containing the analysis of the influence of age factor on the growth and development of children, including during the surgical treatment of diseases and injuries of limbs by Ilizarov.

Method: The data are based on a complex anthropometric and physiological examination of 3150 healthy newborns, 523 children in the postnatal period. In addition, 445 children with achondroplasia and congenital growth retardation of one of the limbs, 230 patients with closed helical fractures of the Shin bones during Ilizarov treatment, and 159 female patients aged 18 to 75 years with initial stages of gonarthrosis were examined.

Results and Discussion: As the age of the sick children increases, periods of adaptive changes aimed at compensating for developmental delays are observed, in particular, the role of arterial hypertension in accelerating growth and microcirculation in tissues is shown.

Conclusion: The relationship between cerebral hemodynamics and motor activity of patients was revealed. It was found that the reduction of motor activity in elderly people can be beneficial in the treatment of bone fractures.
\end{abstract}

Accepted on July 20, 2018

Keywords: Age, Growth of newborns, Compensation for stunting, Arterial hypertension, Treatment of bone fractures, Motor activity.

\section{Introduction}

With increasing age in the human body there is a number of adaptive changes associated with the development and improvement of functions, and in the future - the emergence of adaptive and compensatory mechanisms of regulation. In the surgical treatment of patients of different ages with injuries and orthopedic diseases, the existing structural and functional reserve capabilities of the body are realized. It is important to know the mechanism of this implementation, depending on the age of patients. The aim of the study was to analyze the degree of preservation of adaptive capacity of the body of patients of different ages and their impact on the course of surgical treatment of patients with diseases and injuries of the limbs.

\section{Methods}

The data of own research presented in the review are based on the examination of 3150 healthy newborn children, 57 fetuses with intrauterine growth retardation, 523 healthy children of different ages, 420 boys and girls. In addition, 445 patients with achondroplasia and congenital growth retardation of one of the limbs were examined, as well as 230 patients with closed helical fractures of the Shin bones during Ilizarov treatment and 159 female patients aged 18 to 75 years with initial stages of gonarthrosis. All newborns analyzed the size and weight of the body, as well as indicators of their functional maturity on the Apgar scale. In children and adults examined analyzed the terms of surgical treatment, the level of systemic blood pressure, the rate of capillary blood flow, oxygen tension in the tissues of the tibia, blood flow through the femoral and middle cerebral arteries, self-assessment study of patients using the test SF-36.

\section{Result and Discussion}

It was found that the fertility rate is closely related to the longitudinal body size of women. In the second half of the last century, during the period of acceleration of growth of children with increasing body size of women, their fertility decreased and with the deterioration of the quality of nutrition of the population at the beginning of this century, the normalization of fertility is associated with the observed deceleration of growth [1,2] (Figure 1).

It was found that in patients with congenital malformations (CMF) of one of the lower extremities before birth with body weight less than $3000 \mathrm{~g}$, longitudinal body growth was accelerated, and with greater body weight -begins to steadily lag behind age standards (Figure 2). In the postnatal period, the longitudinal dimensions of the body did not differ from the norm. With a more pronounced lag of the weight-growth

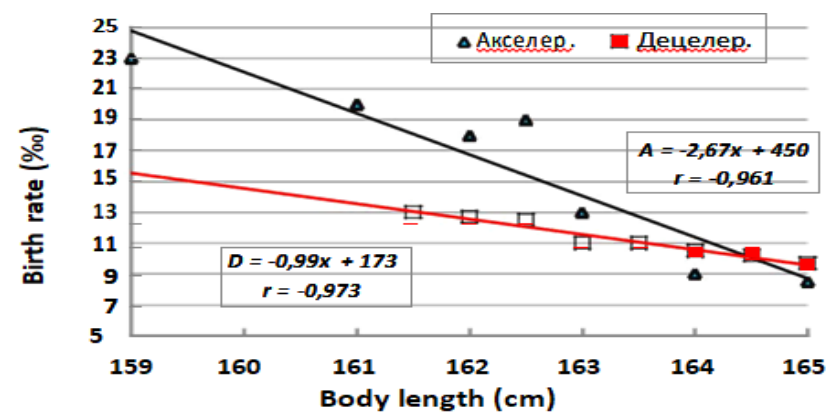

Figure 1. The relationship between the longitudinal body size of women and the birth rate of the population in the XX century and the beginning of the XXI century. 
Citation: Schurov VA. Influence of age factor in the treatment of Ilizarov orthopedic diseases and injuries of the limbs. J Child Adolesc Health. 2018;2(2):9-34.

Table 1. Growth and development of new borns $(M \pm m)$

\begin{tabular}{|c|c|c|c|c|c|c|}
\hline Groups of subjects & Number & Body weight (grams) & Body length (cm) & Apgar-1 & Apgar-2 & Weight-growth index \\
\hline $\begin{array}{c}\text { Healthy } \\
\begin{array}{c}\text { Congenital } \\
\text { malformation }\end{array}\end{array}$ & 535 & $3520 \pm 37$ & $52.8 \pm 0.2$ & $7.46 \pm 0.03$ & $8.55 \pm 0.06$ & 68.8 \\
\hline $\begin{array}{c}\text { Intrauterine growth } \\
\text { retardation }\end{array}$ & 123 & $3020 \pm 109$ & $49.8 \pm 0.4$ & - & - & 69.6 \\
\hline Cerebral palsy & 25 & $2763 \pm 17$ & $49.6 \pm 0.4$ & $7.07 \pm 0.04$ & $8.37 \pm 0.05$ & 55.0 \\
\hline
\end{tabular}

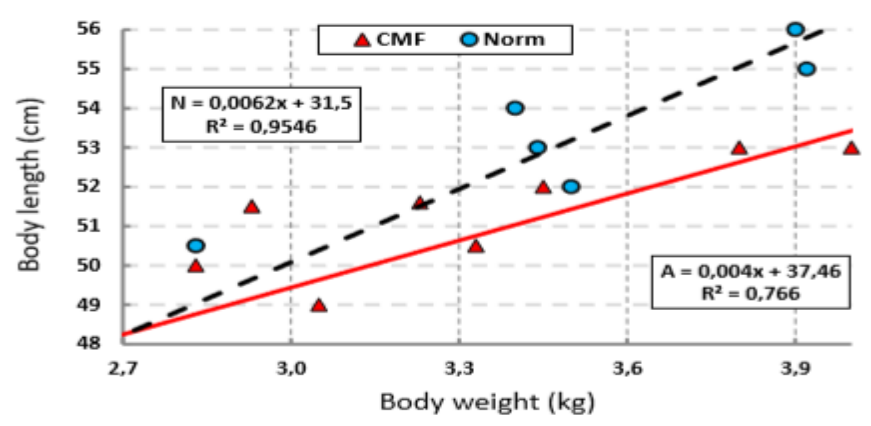

Figure 2. The dependence of the length of the body of new borns on its weight in healthy children and with a congenital lag in the growth of one of the limbs.

index with intrauterine growth retardation (IUGR) and with cerebral palsy (cerebral palsy), there was a lag from the norm of indicators of functional maturity of newborns (Table 1). At the same time, the lag of body weight from the norm remained throughout the postnatal development of children.

It should be noted that in children 8-9 years, the lag in the growth of one of the limbs within $5 \mathrm{~cm}$ can have a moderately pronounced stimulating effect on growth processes, in particular on the longitudinal growth of the body (Figure 3). When shortening more than $7 \mathrm{~cm}$, this corrective effect is mainly negative.

During the period of clinical development of methods of correction of lag in longitudinal growth of the body in patients with achondroplasia due to the operational lengthening of the lower limbs by Ilizarov, lengthening was carried out at the maximum permissible values determined by the need to preserve the contractility of the muscles to provide locomotion in conditions of increasing the It turned out that the greatest opportunities for lengthening open up to 9-11 years, when become less stringent limiting the scope of the genetic growth program. In the future, the permissible values of lengthening, the rate of distraction and the level of recovery of muscle function and the rate of subsequent natural growth of the limb are steadily declining [3]. The greater the age of patients, the less the maximum values of calf lengthening;

$\Delta \mathrm{L}=20-0.36 \times \mathrm{t} ; \mathrm{r}=0.95 ; \mathrm{p} \leq 0.001$.

It is known that during the natural longitudinal growth of the body increases by $40 \%$ blood pressure. However, the acceleration of tissue growth under the influence of increased blood pressure can be observed only in pathological conditions, with the transmission of pressure to the microcirculatory level [4].

It is noted that in case of violation of the growth of one of the limbs there was no negative corrective effect on the growth of symmetrical healthy limbs and on the growth of the trunk. The reason is the development of compensatory hypertension, for example, in the effects of polio [5], in congenital and acquired pathology of the limb [6], which lasts until the end of the period of natural growth of the body.

It was found that in boys and girls, the higher the blood pressure, the greater the body size:

$\mathrm{M}=1.15 \mathrm{x}+16.6 ; \mathrm{r}=0.930$

$\mathrm{W}=0.77 \mathrm{x}+53.5 ; \mathrm{r}=0.959$.

Such an obvious relationship of body growth and growth of blood pressure was not put in mutual dependence for one reason. To hypertension prone people hypersthenic body type, do not differ high growth. We have shown that after the closure of the epiphyseal growth zones, the inversion of the relationship between the longitudinal dimensions of the body and the level of blood pressure occurs (Figure 4).

To restore the disturbed growth of the body in newborns is of great importance relatively large time constant changes in heart size and blood pressure in children with adverse environmental factors. It is the preservation of the parameters of the cardiovascular system that contribute to the appearance of catching-up growth in body weight during recovery and improving the quality of nutrition [7].

The most important factor in the prediction of definitive longitudinal dimensions of limb length is the size of limb segments at the age of 5-6 years. Length, for example, the Tibia in an adult (Ld) the greater than it was in childhood (L5, cm):

$\mathrm{Ld}=-1.84+0.148 \times \mathrm{L} 5$;

$\mathrm{r}=-0.998, \mathrm{p} \leq 0.05$.

The construction of nomograms of the dependence of the final size of the tibia on their length in 5 years allows us to find out that in patients with achondroplasia, the lag in the size of the limbs occurred in early childhood, and in the future, they grow according to the existing General laws. Moreover, it was found that it is particularly sensitive to lag in the length of the tibia. With a rudimentary length of the Shin less than $12 \mathrm{~cm}$, it completely stops growing (Figure 5). When examining patients with gonarthrosis found that with increasing age of women Blood Pressure (BP) they have steadily increased (Figure 6). At the same time, the higher the stage of the disease, the greater the level of systemic blood pressure (Table 2).

The rate of capillary blood flow in the skin of the foot of the intact limb was $1.74 \pm 0.12$ perfusion units. The blood flow rates did not change with increasing age of patients. The rate of peak blood flow was more informative, which was recorded 15 seconds after the termination of 3-minute occlusion of the bringing arteries. If normally it was $5.45 \pm 0.78 \mathrm{p}$. units, then in patients with 1,2 and 3 stages of the disease were reduced by $5 \%, 17 \%$ and $38 \%$, respectively ( $\mathrm{p} \leq 0.05)$. On the intact limb, 


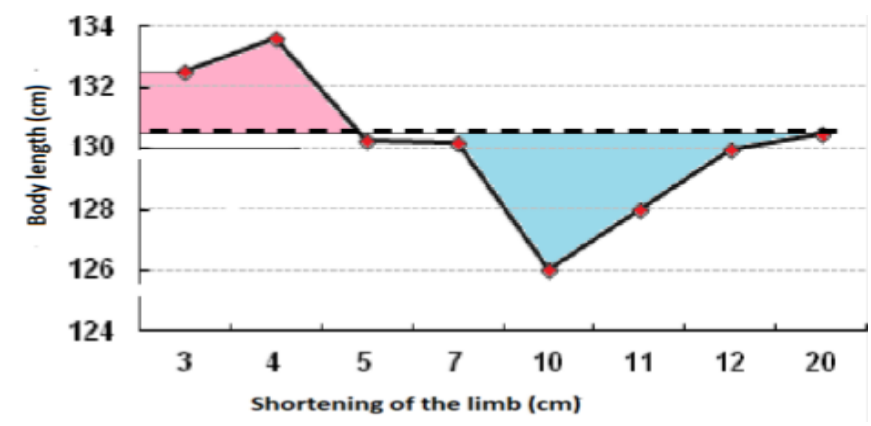

Figure 3. The length of the body in children 8-9 years at different sizes lagging one of the lower limbs in growth.

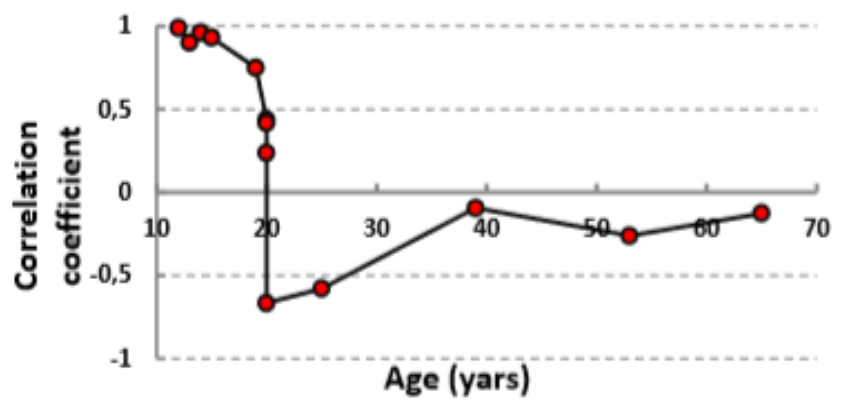

Figure 4. Age dynamics of the coefficient of linear correlation between the level of systolic blood pressure and the longitudinal dimensions of the human body.

the rate of capillary blood flow did not depend on the level of blood pressure. On the disease affected with the development of the disease, the reserve capacity of the microcirculatory tissue bed decreased, and the level of regional blood pressure increased according to the stages of the disease from 135 to 1.2 $\mathrm{mm} \mathrm{Hg}$. $\mathrm{p}$ to $150 \pm 1,3(\mathrm{p} \leq 0,001)$ and up to $155 \pm 1,7 \mathrm{~mm} \mathrm{Hg}$. V. $(p \leq 0.05)$. A direct correlation between the values of blood pressure and the rate of capillary blood flow was revealed:

$\mathrm{Q}=1.12+0.0055 \times \mathrm{P} ; \mathrm{r}=0.630, \mathrm{n}=19$.

It is assumed that the increase in the level of blood pressure in the second adulthood is a manifestation of the protective and compensatory reaction of the body in the face of the threat of deterioration of tissue trophism in diseases and adverse living conditions, which is aimed at stabilizing their blood supply by increasing the value of transfusion pressure. It should be borne in mind that the relationship between the rate of regional blood flow and the value of blood pressure is usually parabolic, that is, the acceleration of blood flow due to the increase in the value of blood pressure is possible within limited limits, until the blood pressure reaches the optimal values, different for healthy and sick people [8].

In humans, during life as the age increases, the oxygen tension in the blood in the tissues of the lower leg decreases $\left(\mathrm{pO}_{2}=57.8\right.$ $-0.2 \times \mathrm{t} ; \mathrm{r}=-0.72$ ).

In addition, there is a decrease in cardiac output minute, the rate of blood flow through the main arteries and the middle cerebral arteries. The rate of decrease in cerebral blood flow is relatively higher in patients with congenital shortening of the limb (Figure 7). The permissible value of speed reduction is $40 \%$ and determines the duration of human viability.

The decrease in the rate of cerebral blood flow is accompanied by an age-related slowdown in the rate of locomotion [9], which is physiologically justified, since it helps to preserve the scope of changes in the blood flow index under functional loads at an optimal stationary level, that is, to implement autoregulation of cerebral hemodynamics [10].

It was found that in the treatment of patients with closed screwlike fractures of the Shin bones in stationary conditions, the longer the period of fixation the more, the older the patients (Figure 8).

In the treatment of outpatients has increased substantially determined by the strain gauge mikrotverdosti of bone fractures and periosteal blood volume of callus. The duration of the fixation period is more significantly increased in patients of working age (Figure 9) and as it is not paradoxical, it is less at people of a retirement age. There is no doubt that the early mobilization of patients and functional loading of the injured limb are useful for treatment [11-13], but, as it turned out, only within certain limits, not beyond the usual patients in the treatment of inpatient conditions $2 \mathrm{~km}$ per day. In conclusion, I would like to note that in healthy people with increasing age there is a deterioration of the SF-36 integral indicator of quality of life $[14,15]$. Even more influence on this indicator has an orthopedic pathology of the limb during surgical treatment for Ilizarov (Figure 10).

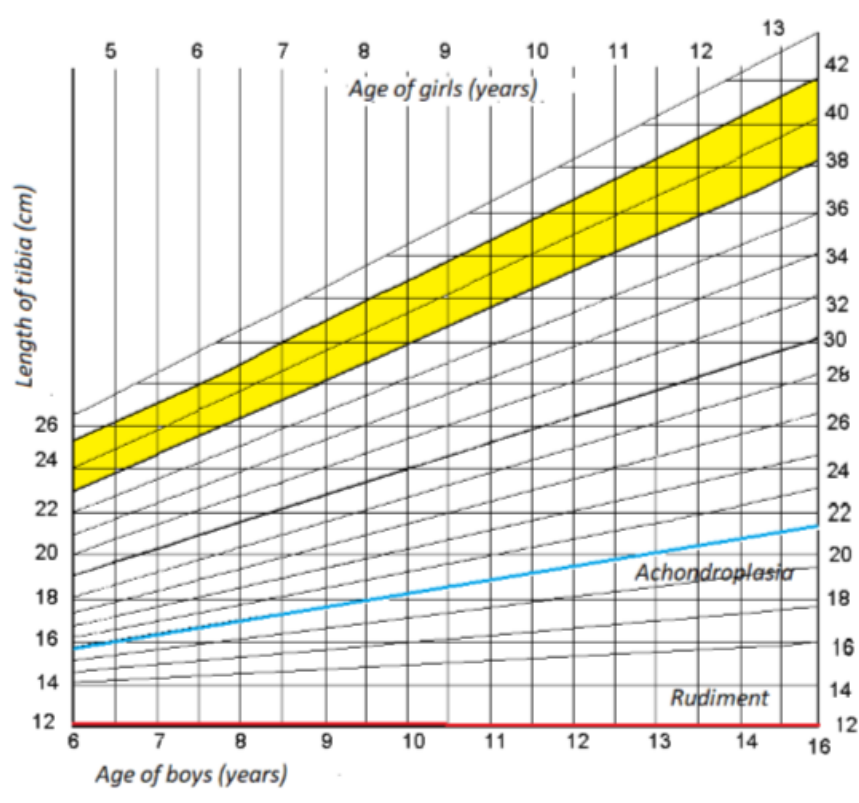

Figure 5. Age dynamics of the longitudinal size of the tibia depending on its initial size in boys and girls.

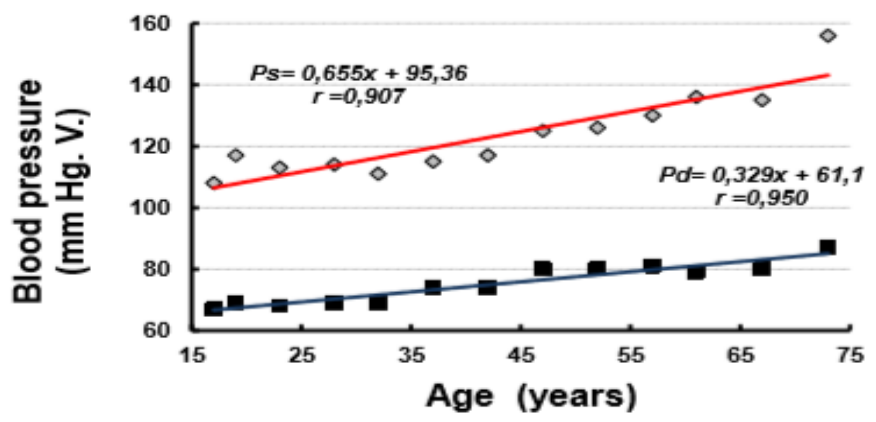

Figure 6. Age dynamics of systolic and diastolic blood pressure in patients with gonarthrosis. 
Citation: Schurov VA. Influence of age factor in the treatment of Ilizarov orthopedic diseases and injuries of the limbs. J Child Adolesc Health. 2018;2(2):9-34.

Table 2: Influence of a stage of osteoarthritis at the level of arterial blood pressure $(M \pm m)$.

\begin{tabular}{|c|c|c|c|c|}
\hline The stage of the disease & The Number & The age & Blood pressure syst. (mm Hg. V.) & Blood Pressure diast. (mm Hg. V.) \\
\hline 1 & 85 & $45 \pm 1.2$ & $119.9 \pm 1.7$ \\
\hline 2 & 59 & $46 \pm 1.5$ & $129.3 \pm 2.0^{*}$ \\
\hline 3 & 9 & $55 \pm 1.9^{*}$ & $140.0 \pm 3.2^{*}$ \\
\hline
\end{tabular}

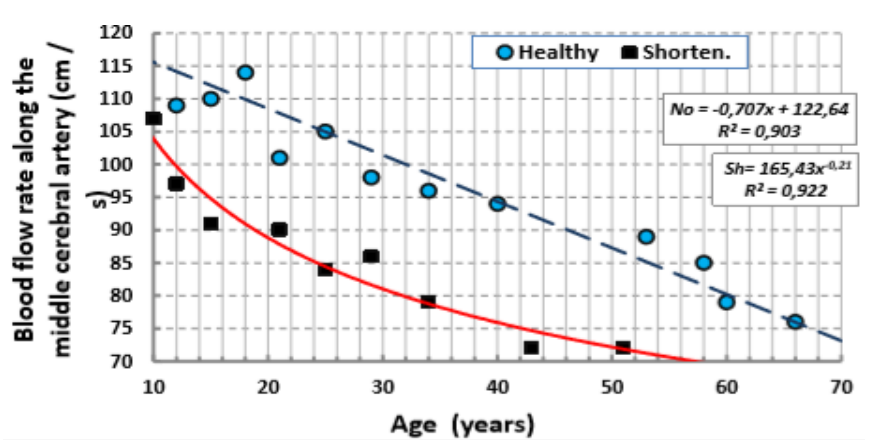

Figure 7. Age dynamics of blood flow in MCA is normal and in patients with congenital shortening of the limbs.

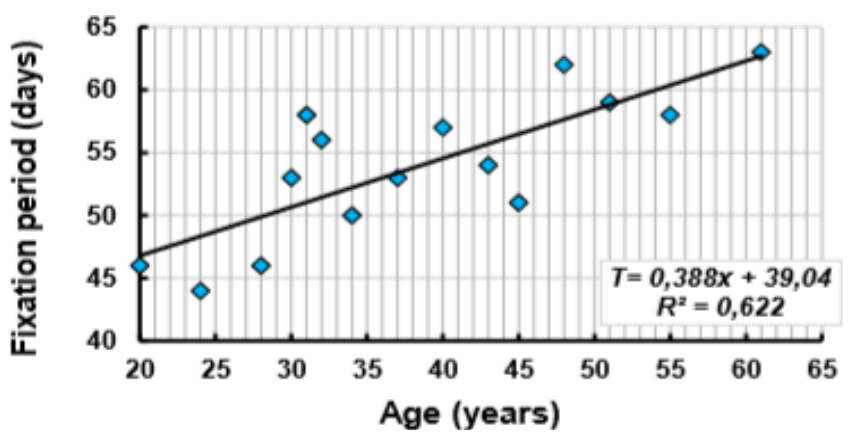

Figure 8. Age dynamics of the duration of the period of fixation in helical fractures of the tibia bones.

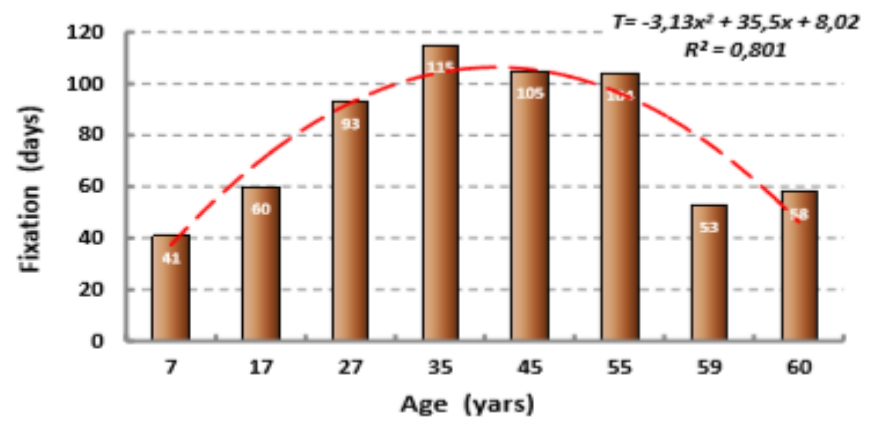

Figure 9. Age dynamics duration of the fixation period in the treatment of patients on an outpatient basis.

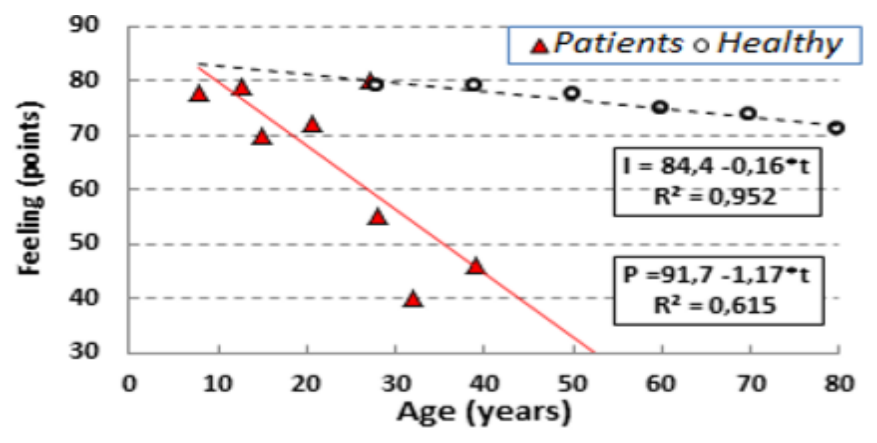

Figure 10. Age dynamics of quality of life in healthy subjects and in patients with limb growth lag during treatment.

\section{Conclusion}

After treatment psychological testing allows to reveal that with the continuing decrease in the level of the block of modules of physical state, the modules of emotional state, cheerfulness in patients with orthopedic pathology, as well as in elderly patients after the healing of fractures become higher than the age norm.

\section{References}

1. Schurov VA, Safonova AV, Mogeladze N. Deceleration of the growth of children as a form of adaptation of the population to the deterioration of quality of life. Bulletin of South Ural state University. 2014;4(33):110-13.

2. Shevtsov VI, Schurov VA. Optimal longitudinal dimensions of the lower extremities. Gen Orthopaed. 2004;(1):83-8.

3. Shurov WA, Muradisinov SO. The second rule of regeneration and leg elongation by Ilizarov. Chir Narz Ruchu Ortop Pol. 1994;59(4):32-8.

4. Kelly PJ, Bronk JT. Venous pressure and bone formation. Microvasc Res.1990; 39(3):364-75.

5. Welner A, Yosipovitch ZH, Groen JJ. Elevated blood pressure in children and adolescents with residual paralysis and deformities from poliomyelitis and other crippling diseases. J Chron Dis. 1966; 19(11):1157-64.

6. Schurov VA, Shevtsov VI, Ivanova TI, Shatokhin VD. Hypertension and longitudinal growth in children and adolescents with diseases of the musculoskeletal system. Pediatrics. 1985;(3):40-42.

7. Bocharova IM, Schurov VA, Sazonova NB. Features of growth of young children born with perinatal pathology of the central nervous system and lower limbs. Gen Orthopaed. 2002;(2):120-22.

8. Schurov VA, Sazonova NB. Pathogenesis of age-related increase in blood pressure in patients with osteoarthritis. Human Physiology. 2008;35(5):83-7.

9. Schurov VA, Pepeliaeva TA. Evaluation of diagnostic information of amplitude characteristics of the pulse of the arteries of the foot. Human Physiology.1992;18(2):139-43.

10. Sorond FA, Galica A, Serrador JM, et al. Cerebrovascular hemodynamics, gait, and falls in an elderly population mobilize Boston Study. Neurology. 2010;74(20):1627-33.

11. Schurov VA. Analysis of the mechanism of age-related decrease in the rate of cerebral blood flow. Regional blood circulation and microcirculation. 2016;15(3):45-50.

12. Claes LE, Wilke HJ, Augat P, et al. Effect of dynamization on gap healing of diaphyseal fractures under external fixation. Clin Biomech. 1995;10(5):227-34. 
13. Goodship AE, Kenwright J. The influence of induced micromovement upon the healing of experimental tibial fractures. J Bone Joint Surg.1985;67(4):650-5.

14. Fleming B, Paley D, Kristiansen T, et al. A biomechanical analysis of the Ilizarov external fixator. Clin Orthop Relat R. 1989; 24:95-105.

15. Hopman WM, Towheed T, Anastassiades T, et al. Canadian normative data for the SF-36 health survey. Can Med Assoc J. 2000;163(3):265-71.

\section{*Correspondence to:}

Schurov VA

Department of Medical Sciences

Ilizarov Research Center for Rehabilitating Traumatology and Orthopedics

Kurgan

Russia

Tel: +7 (3522) 454758

E-mail: shchyrovland@mail.ru 